\title{
Daily precipitation concentration across Europe 1971-2010
}

\author{
N. Cortesi ${ }^{1}$, J. C. Gonzalez-Hidalgo ${ }^{1,2}$, M. Brunetti ${ }^{3}$, and J. Martin-Vide ${ }^{4}$ \\ ${ }^{1}$ Department of Geography, University of Zaragoza, Spain \\ ${ }^{2}$ Instituto Universitario Ciencias Ambientales, University of Zaragoza, Spain \\ ${ }^{3}$ ISAC-CNR, Bologna, Italy \\ ${ }^{4}$ Group of Climatology, University of Barcelona, Spain \\ Correspondence to: J. C. Gonzalez-Hidalgo (jcgh@unizar.es)
}

Received: 1 April 2012 - Revised: 23 July 2012 - Accepted: 14 August 2012 - Published: 11 September 2012

\begin{abstract}
Daily Precipitation Concentration Index (CI) was used in this paper to investigate the statistical structure of daily precipitation across Europe based on 530 daily rainfall series for the period 1971-2010. Annual CI shows a NorthWest to South-East gradient (excluding Turkey and Greece). The same gradient is also observed in winter, spring and autumn, while in summer the gradient is North-South. Highest annual and seasonal daily concentrations of rainfall were detected in the western Mediterranean basin, mainly along Spanish and French coastlands. Latitude and distance from the sea seems to play a major role on spatial CI distribution; at subregional scale also relief plays an important role. The Mann-Kendall test did not identify uniform significant pattern in temporal trend across Europe for 1971-2010 period. The only broad areas with increasing annual and seasonal CI values are located in northern and south-western France and northern coastlands of the Iberian Peninsula. This findings suggest that daily precipitation distribution has not significantly changed during the 1971-2010 over Europe.
\end{abstract}

\section{Introduction}

Daily precipitation is a discrete process (rain or no rain), and it is well represented by an exponential negative distribution (Brooks and Carruthers, 1953). This means that there are many days with a low amount of precipitation and few intense events. Therefore, a few daily events produce a high percentage of the total monthly, seasonal or annual precipitation (Martin-Vide, 2004), with effects on natural systems (erosion, flooding, droughts), man-made systems (design of storm water drainage, planning and design of transport networks, etc.), and also socioeconomic infrastructures (water harvesting, water surplus, etc.). Toreti et al. (2010) have recently suggested that the contribution of the maximum daily value exceeds more than $60 \%$ of winter rainfall around the Mediterranean basin, and Gonzalez-Hidalgo et al. (2011a) extended this result to annual totals in the same area. Thus, in some parts, total precipitation depends on a few rainy days, i.e. precipitation is a very highly time-compressed process.

A great deal of research has been carried out on daily precipitation, focusing on extreme events by means of a very heterogeneous spectrum of analysis methods, such as indices, percentiles, thresholds, and extreme value theory (Groisman et al., 2005), and it is not easy to compare different results (see discussions in Reiser and Kutie, 2010; Toreti et al., 2010; and Durao et al., 2010 among others for definitions and concepts). However, little information is available on the daily concentration of precipitation, mainly because of lack of high quality daily precipitation datasets (Brunetti et al., 2000, 2001, 2004, 2012; Brugnara et al., 2012; Reiser and Kutiel, 2010). Some exceptions are the research in Spain by Martin-Vide (2004), who proposed a Concentration Index, later applied by Alijani et al. (2007) in Iran and by Zhang et al. (2009) in China, and the recent research by Burgueño et al. (2010) in Europe.

Empirical studies do not show homogeneous results in the analyses of temporal concentration of precipitation when comparing the total annual precipitation trend and the trend of highest daily event categories. Karl et al. (1996) and Karl and Knight (1998) have shown that there is an increase in the relative contribution of intense precipitation in USA, but not in the former USSR and China. Positive trends in heavy rainfall in summer and winter have been found in Australia and South Africa (Suppiah and Hennnessy, 1998; Mason et al., 1999), in annual maximum 1-day precipitation over Nordic countries (Forland et al., 1998), and in UK winter daily intensity but not in summer (Osborn et al., 2000). Klein-Tank and Konnen (2003) found that there has been a general increase in annual extreme precipitation across Europe over 
the period 1946-1999, while Haylock and Goodess (2004) showed that the trends of the number of days above the 1961-1990 90th percentile of wet-day amounts have different signs, due to the heterogeneous nature of the region. In southern Europe, mostly across the Mediterranean basin, it has been suggested that the heaviest rainfall events, or the contribution of heaviest events to the annual total, have increased in western areas (Brunetti et al., 2000, 2001, 2004; Alpert et al., 2002; Gonzalez-Hidalgo et al., 2003; Costa and Soares, 2009), but this result is strongly dependent on the period examined (Brunetti et al., 2012; Brugnara et al., 2012); on the contrary, in the eastern areas, no significant trend has been detected in the number of intense or extreme events (Zang et al., 2009; Kioutsioukis et al., 2010).

Finally, other studies found no significant trend for higher percentiles of daily precipitation, number of wet days, contribution of extreme events, etc. across the Mediterranean basin (Norrant and Douguedroit, 2006; Moberg et al., 2006; Gallego et al., 2006; Brunet et al., 2007; Rodrigo and Trigo, 2007; Durao et al., 2010; Toreti et al., 2010). Thus, Reiser and Kutiel (2010) concluded that no generalized temporal changes have been detected in the daily rainfall regime across the Mediterranean basin, but the results depend on density of observations, study period, and area analysed; therefore, several trends in the probability of various daily rainfall categories have been suggested (Rodrigo, 2010).

Model projections suggest that precipitation variability will increase at the end of the 21 st century as a consequence of global hydrological cycle enhancement and the increase of intense precipitations (Lionello and Giorgi, 2007). As a general rule, the models suggest no change or increase in the number of rainy days in northern areas of Europe; whereas in southern areas the number of rainy days will decrease, but heavy precipitation is expected to increase and become more variable (Räisänen et al., 2004; Zolina et al., 2004; Kundzewicz et al., 2006; Burgueño et al., 2010). Thus, the analysis of daily precipitation distribution and its effects on temporal concentration across Europe is an important issue in climate research.

In this study we have analysed the time compression of precipitation by means of the precipitation concentration index (CI) proposed by Martin-Vide (2004). The analysis was performed in Europe across the continental climatic gradient from circumpolar to subtropical (Mediterranean) climate types (latitudinal gradient north-south), and from oceanic coastland to inland (continental) climate types (west-east gradient). The analysis was performed on an annual and seasonal scale, using massive information from several daily sources. In order to study the temporal stability of the CI, we analysed the trend of annual and seasonal values of the CI. The results are discussed in terms of spatial gradients and temporal changes in the daily distribution of rainfall.

\section{Data series}

Europe is one of the most suitable places in which to analyse temporal concentration of precipitation because of the availability of daily precipitation information, station density and quality of data. A total of 744 daily precipitation series across Europe were checked from three different datasets: the European Climate Assessment (ECA) \& Dataset (Klein-Tank et al., 2002, updated by Klok and Klein-Tank, 2008) ${ }^{1}$, the National Oceanic and Atmospheric Administration (NOAA) ${ }^{2}$, and the Spanish Agencia Estatal de Meteorologia (AEMet) ${ }^{3}$. To ensure the highest data availability, we selected the most recent period 1971-2010, and only series with less than 10\% of missing data. Only those series of the ECA dataset that passed the ECA criteria of quality control were accepted; for AEMet Spanish stations, we considered only those series that returned homogeneous results within the frame of the MOPREDAS (MOnthly PRecipitation DAtaset of Spain) dataset homogenization (Gonzalez-Hidalgo et al., 2011b); finally, for NOAA series, we checked the homogeneity by using SNHT (Alexandersson, 1985) with a reference series, and all series requiring any kind of correction were discarded from the dataset. The final number of series was 298 for ECA, 51 for AEMet and 181 for NOAA.

The distribution of stations within the study area is generally very good, as they are spaced apart fairly evenly and cover almost the whole area. The only European countries with a low station density or no data available at all are Bulgaria (west of the Black Sea), Georgia and Armenia (east of the Black Sea), as well as eastern Sweden. Figure 1 shows the spatial coverage and the origin of series.

\section{Method}

In the study of the daily concentration of precipitation across Europe, we used the concentration index (CI) proposed by Martin-Vide (2004). The CI is based on the fact that the contribution of daily rainfall events to total amount is generally well described by a negative exponential distribution (Brooks and Carruthers, 1953). The method consists of aggregating daily precipitation events into increasing ( 1 by $1 \mathrm{~mm}$ ) categories and determining the relative impact of the different classes by analysing the relative contribution (as a percentage) of progressively accumulated precipitation, $Y$, as a function of the accumulated percentage of wet days, $X$, as defined by the following Eqs. (1) and (2):

$$
Y_{j}=100 \cdot \frac{\sum_{i=1}^{j} p_{i}}{\sum_{j=1}^{N} p_{j}}
$$

\footnotetext{
${ }^{1}$ http://eca.knmi.nl/dailydata/index.php

${ }^{2} \mathrm{fttp} / / / \mathrm{ftp} . \mathrm{ncdc}$.noaa.gov/pub/data/gsod/

${ }^{3} \mathrm{http} / / /$ www.aemet.es/es/servidor-datos/acceso-datos
} 


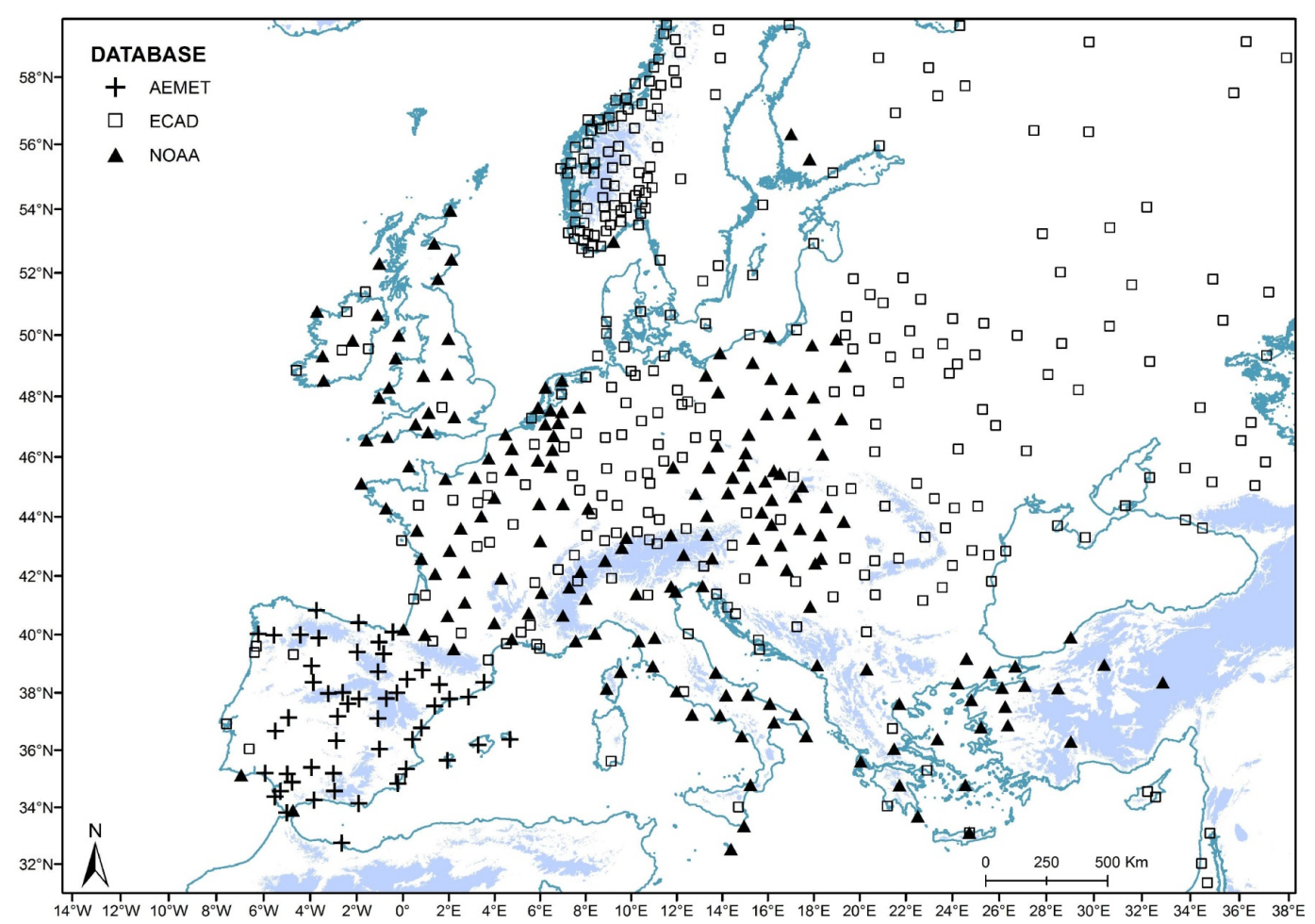

Fig. 1. European rain gauge network after quality controls.

and

$X_{j}=100 \cdot \frac{\sum_{i=1}^{j} n_{i}}{\sum_{j=1}^{N} n_{j}}$,

where $p_{i}$ and $n_{i}$ are the precipitation and the number of wet days (respectively) falling into the $i$-th category, and $N$ is the total number of categories. These percentages are related to exponential curves, called normalized rainfall curves (Jolliffe and Hope, 1996), so the above-mentioned method can be improved by substituting the empirical lines with the fitted exponential curves. The works of Riehl (1949) and Olascoaga (1950) showed that such functions have the form

$\hat{Y}=a \hat{X} \cdot e^{b \hat{X}}$,

where $a$ and $b$ are constants that can be determined by means of the least-squares method in Eqs. (4) and (5):

$\operatorname{In} \alpha=\frac{\sum X_{i}^{2} \sum \operatorname{In} Y_{i}+\sum X_{i} \sum X_{i} \operatorname{In} X_{i}-\sum X_{i}^{2}-\sum \operatorname{In} X_{i}-\sum \operatorname{In} X_{i} \sum \operatorname{In} Y_{i}}{N \sum X_{i}^{2}-\left(\sum x_{i}\right)^{2}}$

and

$b=\frac{N \sum X_{i} \operatorname{In} Y_{i}+\sum X_{i} \sum \operatorname{In} X_{i}-N \sum X_{i} \operatorname{In} X_{i}-\sum X_{i} \sum \operatorname{In} Y_{i}}{N \sum X_{i}^{2}-\left(\sum x_{i}\right)^{2}}$

and this was used to fit the empirical couples of values $\left(X_{j}, Y_{j}\right)$ defined above.
Examples of the annual empirical curves or "concentration curves" of $Y$ vs. $X$ for London and Valencia stations are presented in Fig. 2 together with the fitted exponential curves. The two sites present strongly different daily precipitation regimes. The city of Valencia is located in the east of Spain and precipitation there has a higher concentration and is more irregular than in London. The concentration can be considered a function of the relative separation of the equidistribution line, which is greater in Valencia than in London.

Once both constants $a$ and $b$ have been determined, the normalized daily precipitation concentration index can be defined as follows:

$\mathrm{CI}=S / 5000$,

where $S$ is the area delimited by the exponential curve, and the line $Y=X$ is

$S=(10000 / 2)-A$,

with $A$ being the definite integral of the exponential curve $a X \cdot e^{b X}$ between 0 and 100 (the range of allowed values for $X$ ), i.e. the area under the curve

$A=\left[\frac{a}{b} e^{b x}\left(x-\frac{1}{b}\right)\right] \begin{gathered}100 \\ 0\end{gathered}$

The annual CIs for the London and Valencia stations are 0.59 and 0.71 , respectively. Note also that, by definition, the 


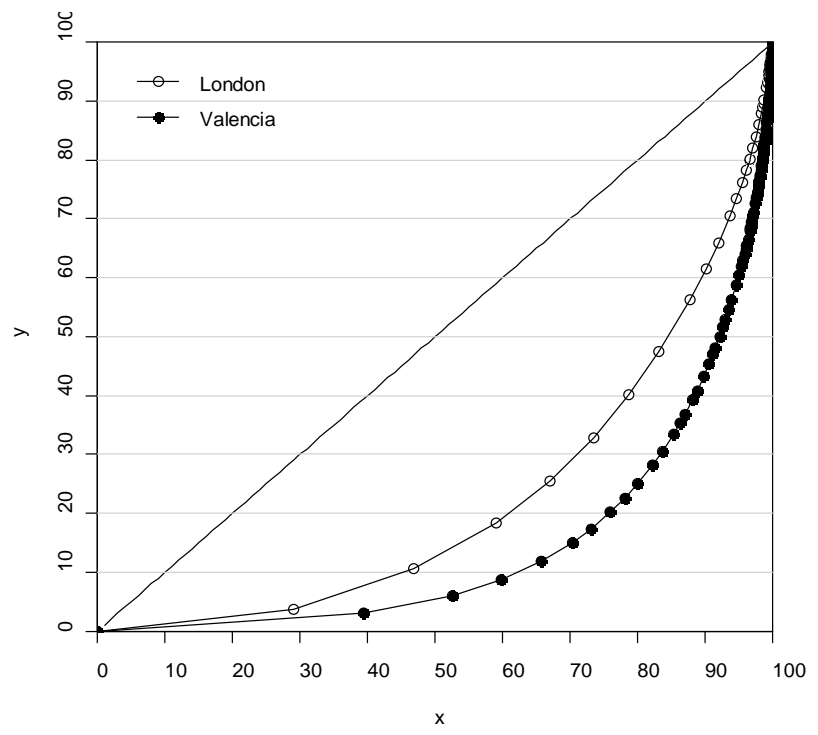

Fig. 2. Empirical and fitted concentration curves for London and Valencia (1971-2010).

value of the $\mathrm{CI}$ is always a number between 0 and 1 , and geometrically it represents the percentage of the triangle area between the line $Y=X$ and the exponential curve. The $\mathrm{CI}$ is virtually equal to 0 when the contribution of each category of precipitation to the total is the same (i.e. when the exponential curve is $Y=X$ ), and equal to 1 when precipitation falls into one category only and the exponential curve converts to the straight line $Y=0$.

Exponential curves of this type were calculated for all meteorological stations across Europe for the period 19712010, both annually and seasonally. In addition, we analysed the associated trends of CI time series from 1971 to 2010 on annual and seasonal scales. Only series with less than $10 \%$ missing data on seasonal and annual scales were used to calculate $\mathrm{CI}$ indexes.

Finally, a two-tailed Mann-Kendall non-parametric test was introduced to detect significance of trend in CI time series from 1971 to 2010, in order to avoid non-normality of series (Zhang et al., 2009), and a threshold of $p<0.10$ as the level of significance was chosen. Given the scarcity of rainy events in southern Europe, particularly in summer, a lower limit of a minimum of 3 precipitation categories was required to compute $\mathrm{CI}$ indexes for all seasons. Thus, every empirical curve (such as in Fig. 2) is defined by at least three points.

\section{Results}

\subsection{Daily concentration index across Europe}

The annual CI index ranges, between 0.51 and 0.72 , are spread across Europe in a broad north-west to south-east gradient (Fig. 3). The maximum value was found in Perpignan (France, $42^{\circ} 42^{\prime} \mathrm{N}, 2^{\circ} 55^{\prime} \mathrm{E}$ ), while the lowest was in Kirkwall (UK, $58^{\circ} 59^{\prime} \mathrm{N}, 2^{\circ} 58^{\prime} \mathrm{W}$ ). The highest annual daily concentrations of rainfall were detected primarily in the western Mediterranean basin (along the Spanish and French Mediterranean coasts) and Sicily, and secondary maximum annual values were found around the Black Sea, especially in Romania, Moldavia and western Ukraine. On the other hand, countries with the lowest annual precipitation CI values are the north-west coast of Norway, Great Britain, Ireland, Netherlands and Denmark. Thus, there is a kind of "dipole" with poles located around the North Sea and the western Mediterranean basin. The strongest gradient occurs between the north and south of France and between the northwest and south-east of Spain. The maritime mid-latitude climate meets the Mediterranean climate in these two countries.

Seasonal values of CIs range between 0.48 in winter (Orskoh, Norway) to 0.88 during summer (Luqa, Malta), with $95 \%$ of values ranging from 0.55 to 0.67 . The spatial gradients for winter, spring and autumn are similar to the annual one, lying from the north-west to the south-east, while the summer pattern exhibits a north to south gradient (Figs. 4, $5,6,7)$. The North Sea-western Mediterranean "dipole" is visible on all the maps. The spatial differences between summer and the other seasons are particularly clear on the Iberian Peninsula and in western France.

In general terms, both the annual and seasonal spatial distribution are geographically consistent. The value of 0.67 (high) means that the wet days belonging to the highest quartile account for more than $75 \%$ of total amount. With CI values higher than 0.70 , the accumulated fraction of precipitation in the highest quartile is close to $80 \%$ or more.

The Pearson correlation (r) for mean annual wet days and annual CIs is $-0.68(p<0.01)$ and clearly significant, coinciding with the decrease in the number of rainy days between north and south Europe, while the $\mathrm{r}$ value between annual mean precipitation and annual $\mathrm{CI}$ is -0.31 . This result is expected since annual precipitation is not a clear indicator of the time compression of precipitation, because similar annual values could be achieved with different daily distributions.

\subsection{Trends in daily precipitation concentration}

The results of trend analyses are shown in Table 1. The CI trend is mainly positive on an annual and seasonal scale, but the level of significance is very low. Only $6.8 \%$ of stations return a negative significant trend, varying between $4.5 \%$ and $6.0 \%$ at seasonal level, while the percentage of stations with a significant positive trend is higher than for the negative (between $13.2 \%$ and $18.9 \%$ on a seasonal scale, and $23.8 \%$ on an annual scale).

The spatial distribution of trends indicates heterogeneity across Europe, with no global patterns on an annual scale (Fig. 8). Generally, the east of Europe (more continental) has fewer stations with significant trends than the west. 


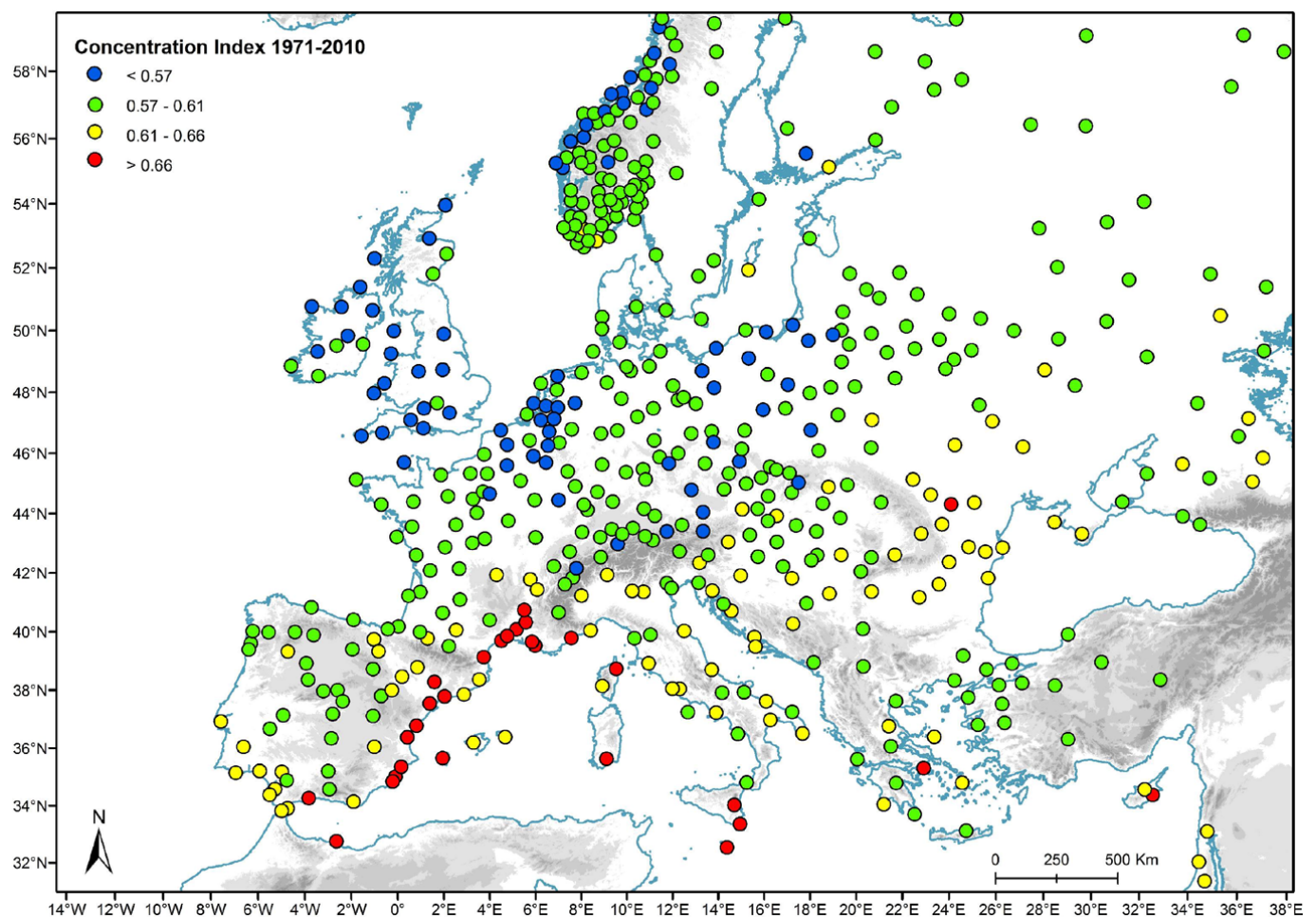

Fig. 3. Annual CI values distribution. Each colour corresponds to a different interval: CI values 0.56 or lower (blue dots), between 0.57 and 0.61 (green dots), between 0.62 and 0.66 (yellow dots), and 0.67 or higher (red dots).

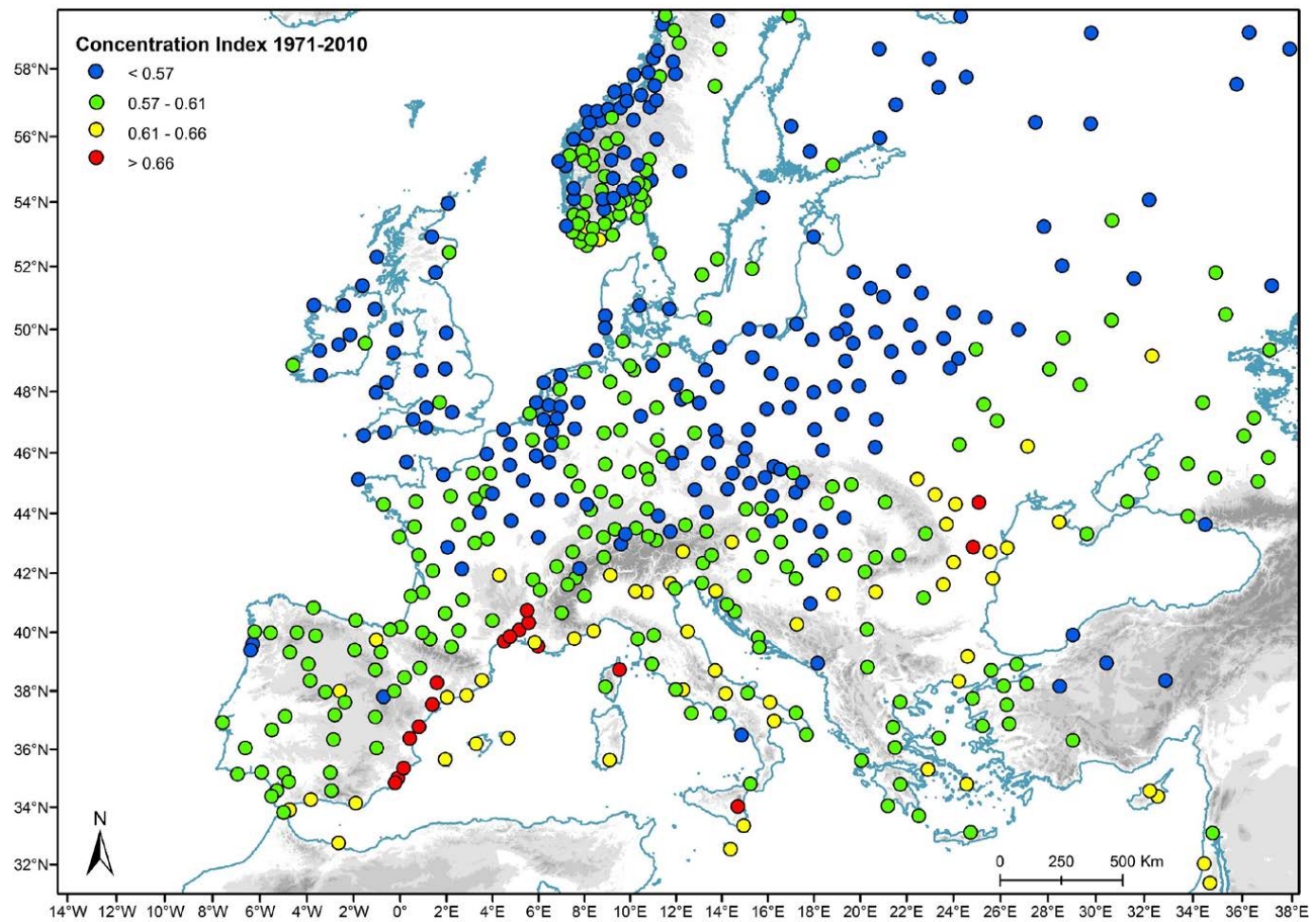

Fig. 4. Winter CI values distribution. Each colour corresponds to a different interval: CI values 0.56 or lower (blue dots), between 0.57 and 0.61 (green dots), between 0.62 and 0.66 (yellow dots), and 0.67 or higher (red dots). 


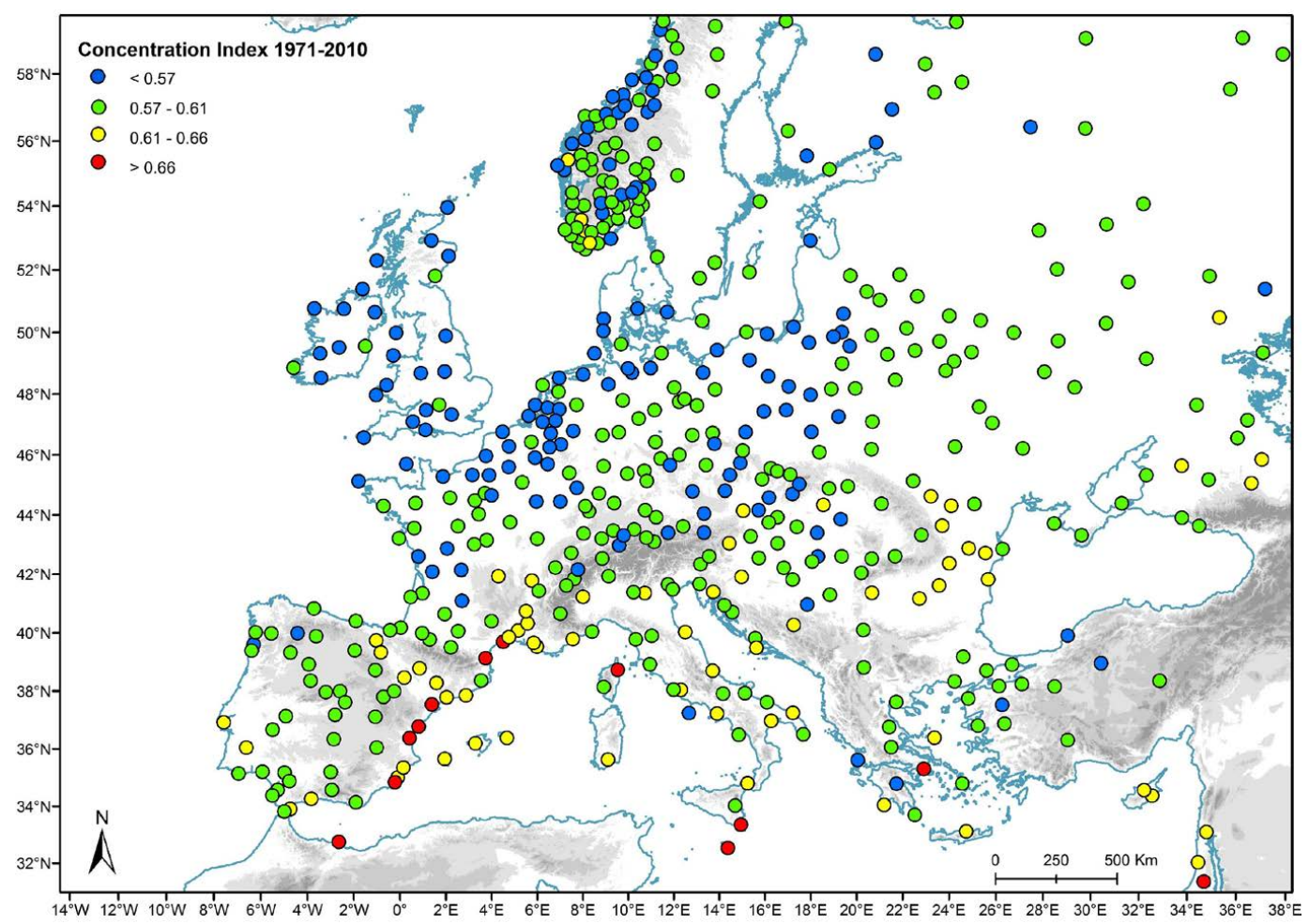

Fig. 5. Spring CI values distribution. Each colour corresponds to a different interval: CI values 0.56 or lower (blue dots), between 0.57 and 0.61 (green dots), between 0.62 and 0.66 (yellow dots), and 0.67 or higher (red dots).

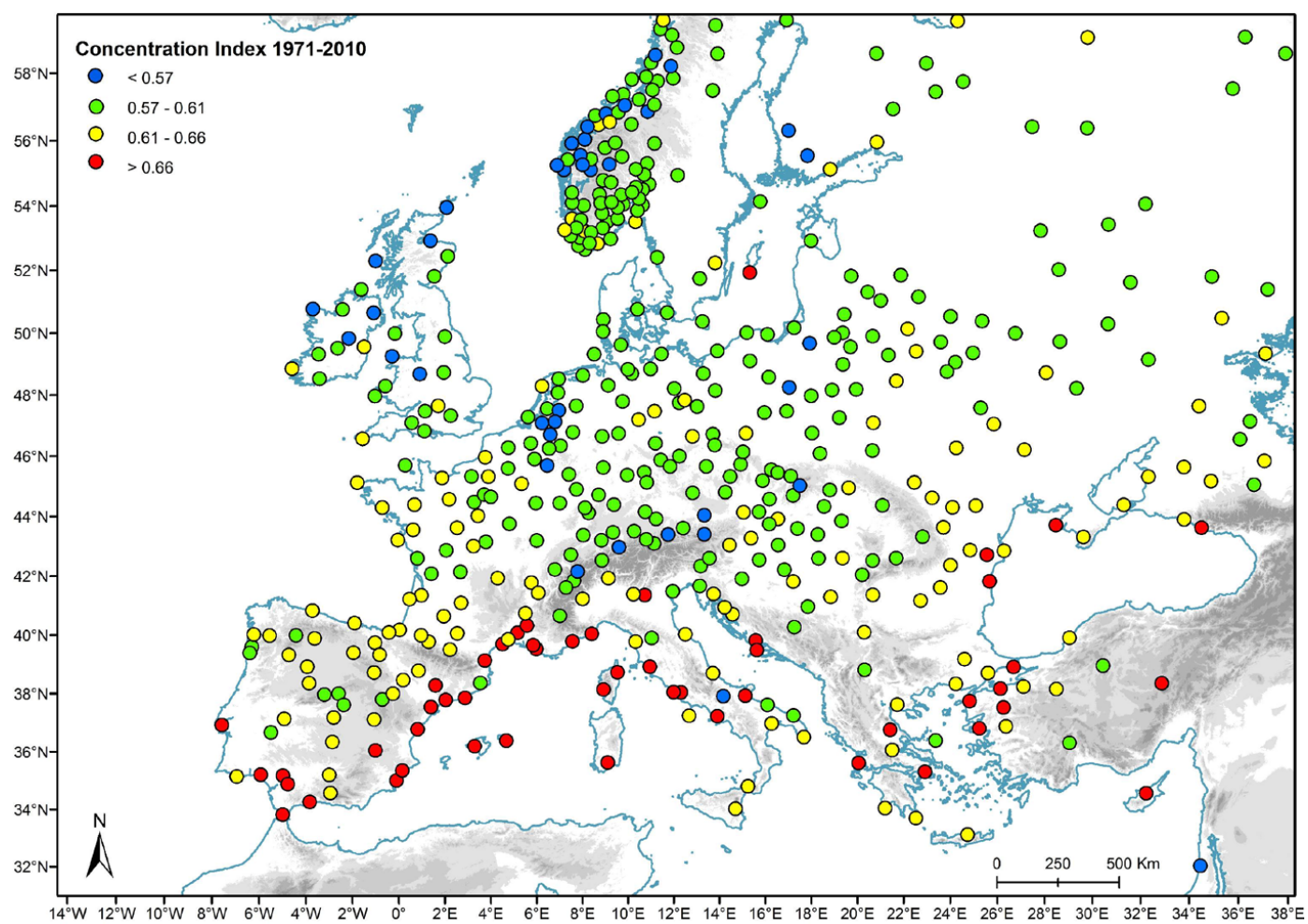

Fig. 6. Summer CI values distribution. Each colour corresponds to a different interval: CI values 0.56 or lower (blue dots), between 0.57 and 0.61 (green dots), between 0.62 and 0.66 (yellow dots), and 0.67 or higher (red dots). 


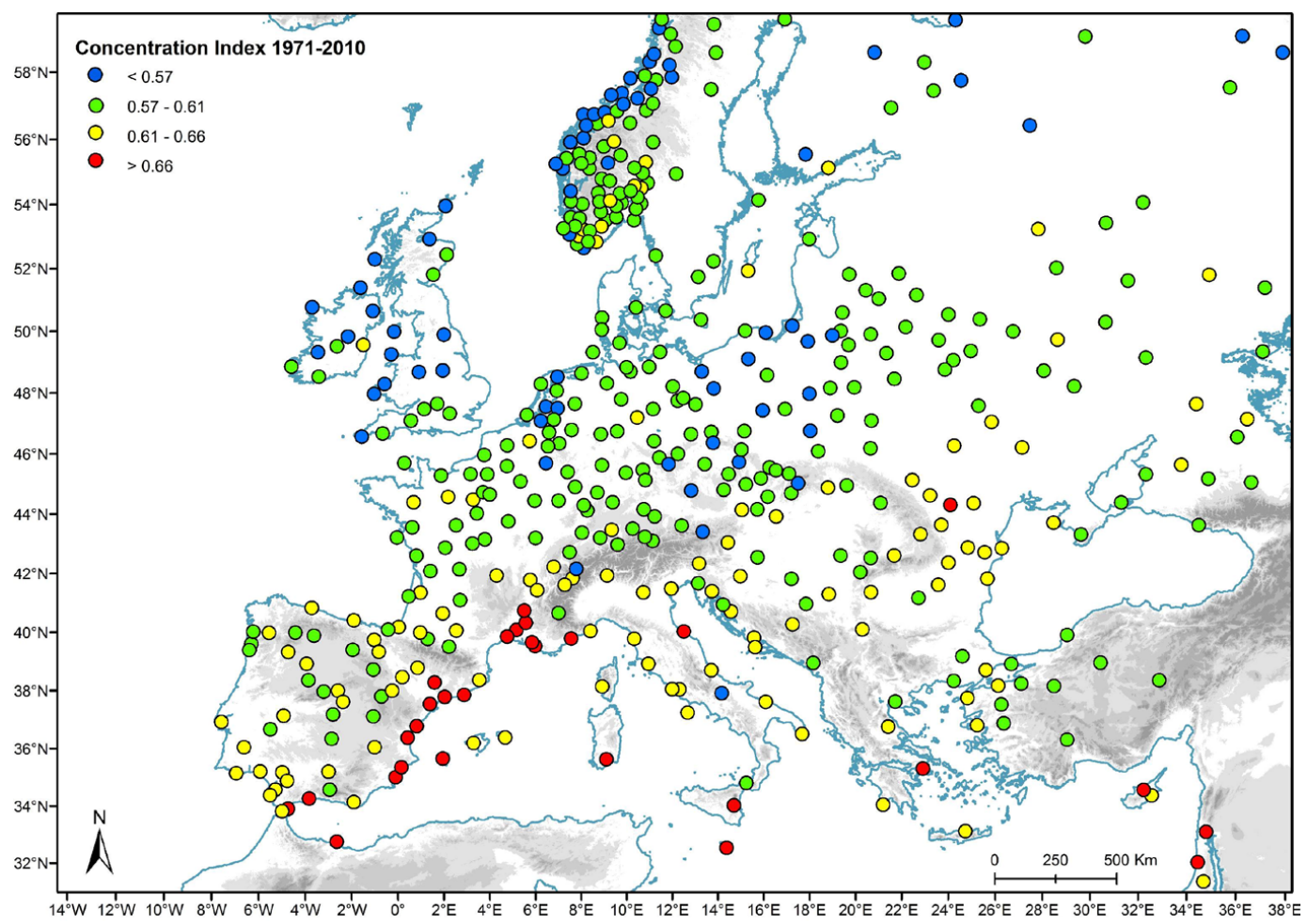

Fig. 7. Autumn CI values distribution. Each colour corresponds to a different interval: CI values 0.56 or lower (blue dots), between 0.57 and 0.61 (green dots), between 0.62 and 0.66 (yellow dots), and 0.67 or higher (red dots).

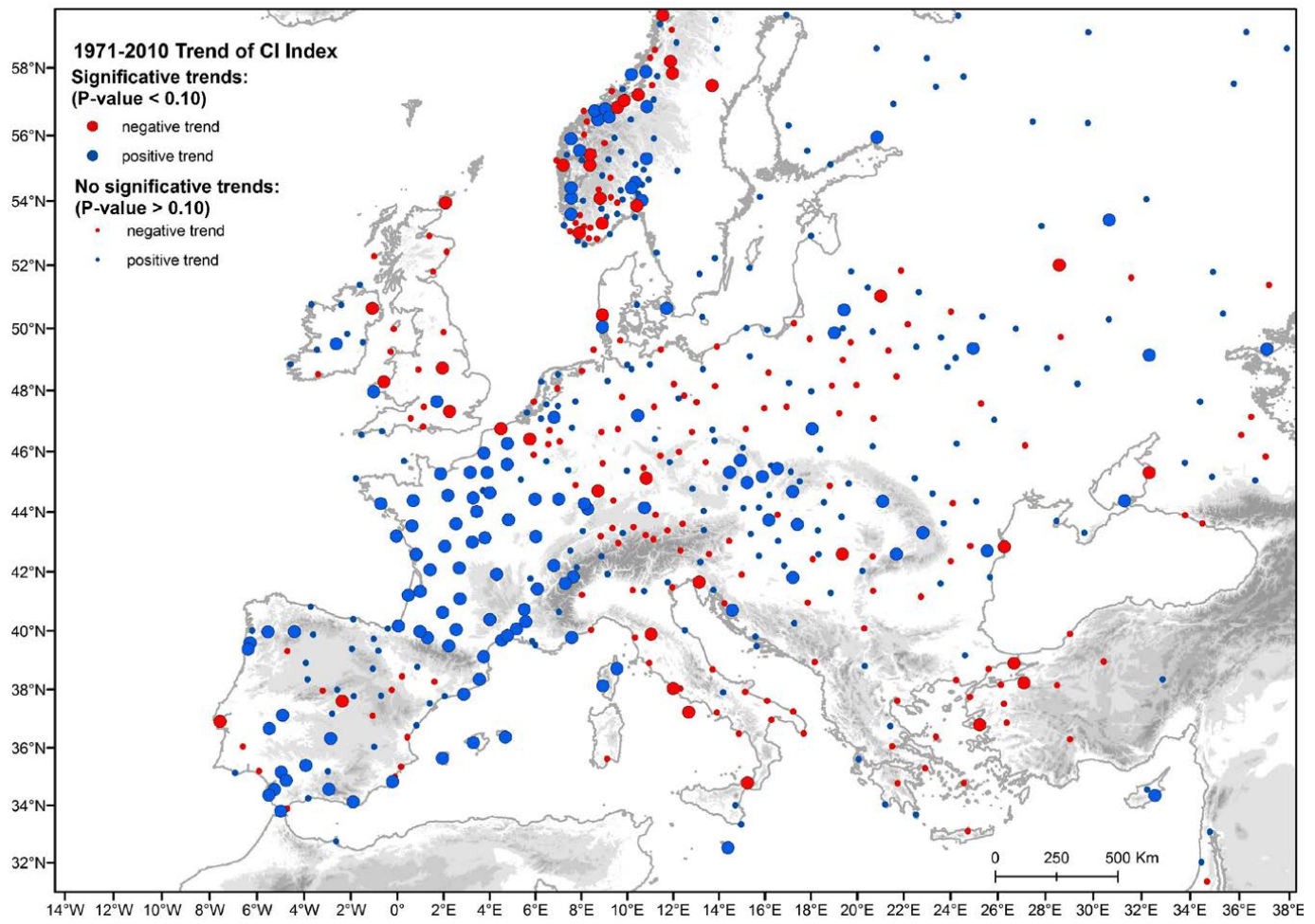

Fig. 8. Annual CI trend distribution (1971-2010). Positive trends are in blue and negative ones in red. Large dots represent significative trends $(p<0.10)$, otherwise small dots are shown. 


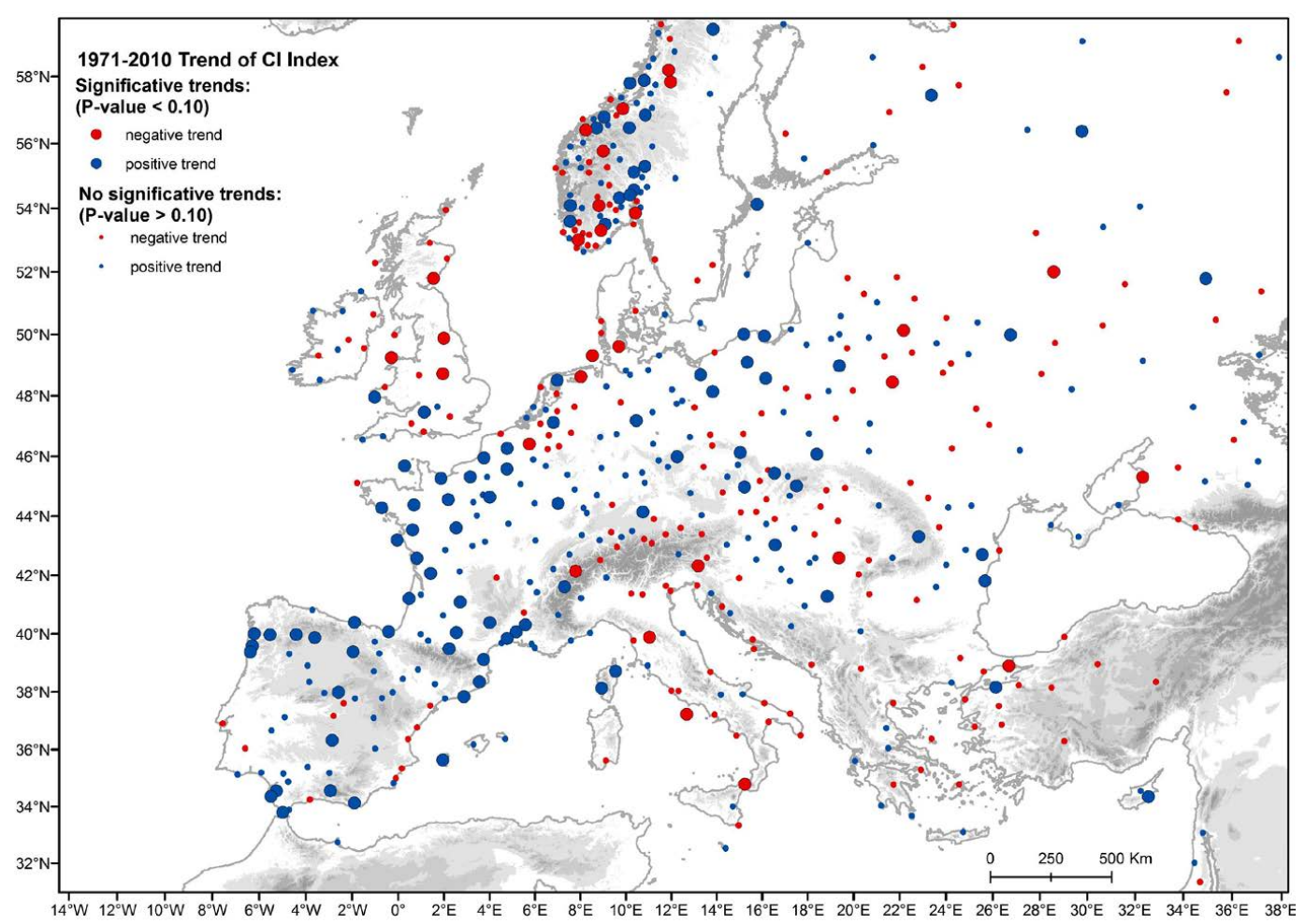

Fig. 9. Winter CI trend distribution (1971-2010). Positive trends are in blue and negative ones in red. Large dots represent significative trends $(p<0.10)$, otherwise small dots are shown.

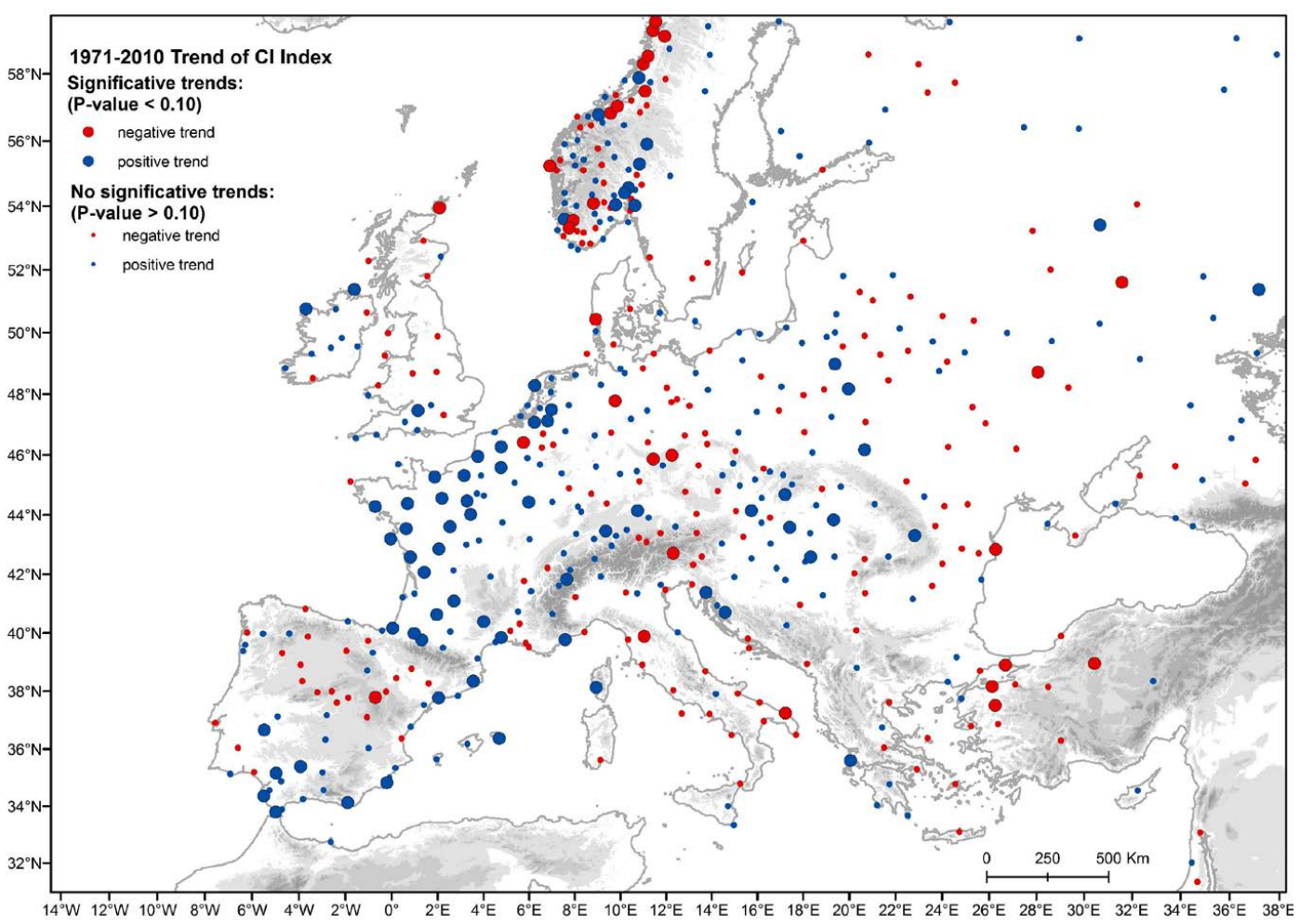

Fig. 10. Spring CI trend distribution (1971-2010). Positive trends are in blue and negative ones in red. Large dots represent significative trends $(p<0.10)$, otherwise small dots are shown. 


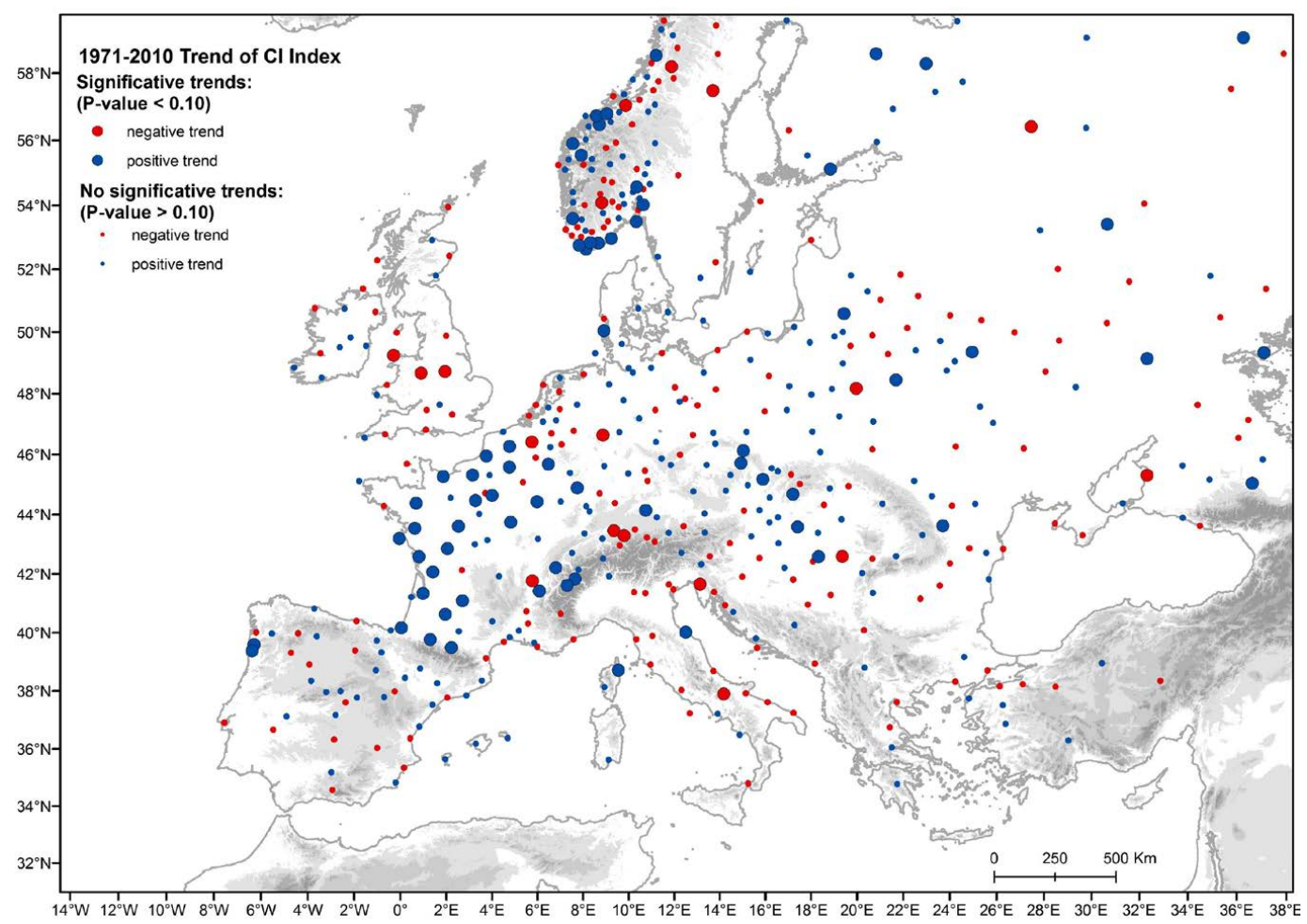

Fig. 11. Summer CI trend distribution (1971-2010). Positive trends are in blue and negative ones in red. Large dots represent significative trends $(p<0.10)$, otherwise small dots are shown.

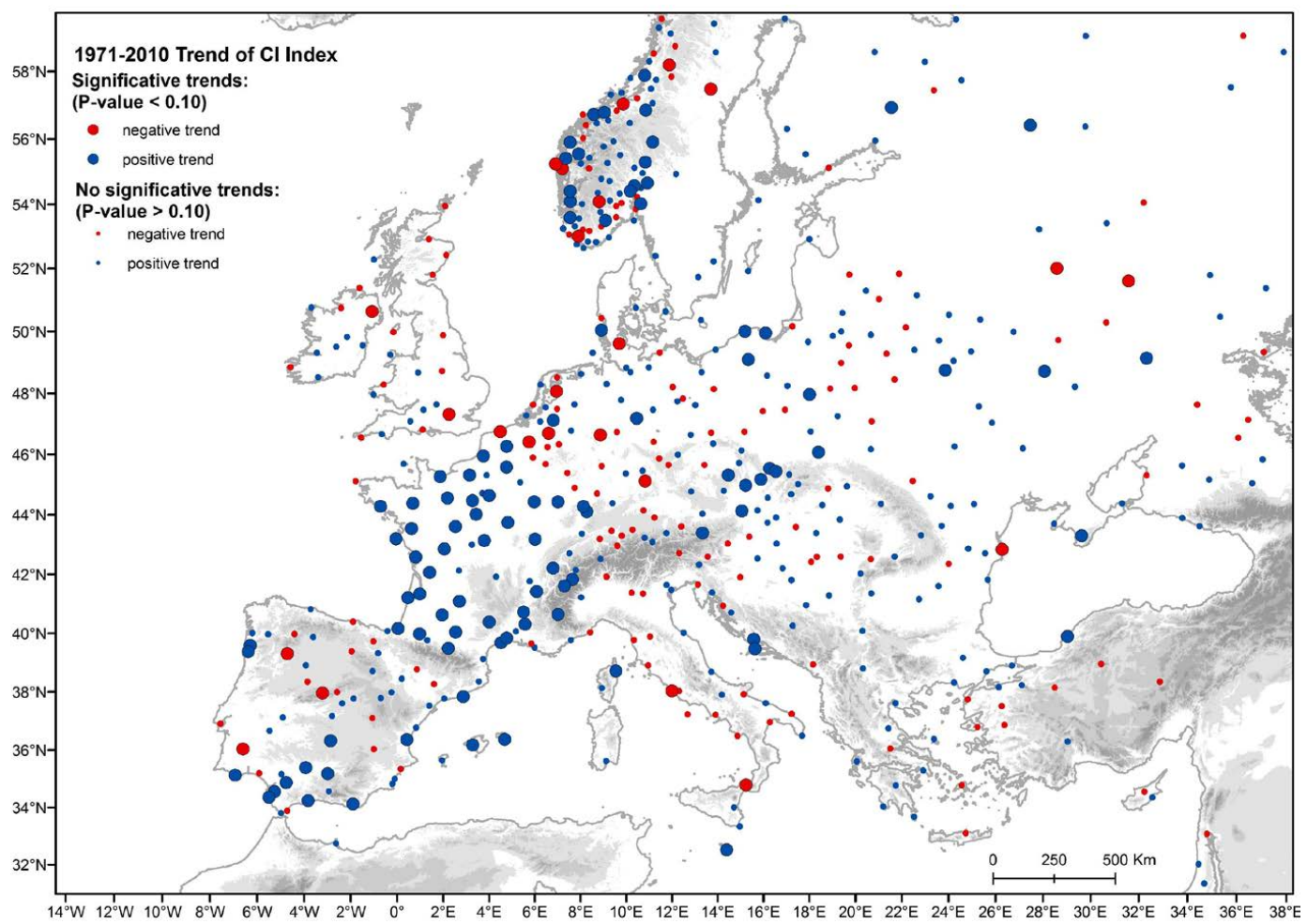

Fig. 12. Autumn CI trend distribution (1971-2010). Positive trends are in blue and negative ones in red. Large dots represent significative trends $(p<0.10)$, otherwise small dots are shown. 
Table 1. Trend analyses of CI. Number of stations by trend signal and level of significance $(p<0.10)$.

\begin{tabular}{lllllll}
\hline & & Year & Winter & Spring & Summer & Autumn \\
\hline \multirow{2}{*}{ Number of series by trend signal } & Negative & 200 & 212 & 302 & $215(*)$ & 172 \\
& Positive & 330 & 318 & 228 & 285 & 358 \\
\hline \multirow{2}{*}{ Number of series with significant trend } & Negative & 36 & 28 & 32 & 26 & 24 \\
& Positive & 126 & 95 & 72 & 70 & 100 \\
\hline \multirow{2}{*}{ Percentage of series with significant trend } & Negative & $6.8 \%$ & $5.3 \%$ & $6.0 \%$ & $4.9 \%$ & $4.5 \%$ \\
& Positive & $23.8 \%$ & $17.9 \%$ & $13.6 \%$ & $13.2 \%$ & $18.9 \%$ \\
\hline
\end{tabular}

$(*)$ the total number of series is reduced by 30 because of 0 values (see text)

The seasonal analysis does not reveal a clear pattern either (Figs. 9, 10, 11 and 12). However, on annual, winter, and autumn scales, the percentage of stations with significant positive trends is higher than the percentage of those with significant negative trends. In spring and summer the difference is smaller, the positive significant trends being between two and three times more than the negative ones.

On a local scale, it is interesting to highlight that France has a general positive significant trend on annual and, to a lesser extent, seasonal scales. In Norway, both on annual and seasonal scales, there are stations with a significant annual increase in the $\mathrm{CI}$ along the western coastline, and others with a significant annual decrease, mainly inland and along the south coast.

\section{Discussion}

Precipitation is one of the factors in the processes of creating landscape, and thus differences in temporal distribution of precipitation can lead to different precipitation regimes and various climatic conditions affecting landscapes processes, even if annual total amounts are similar. Many places in southern Europe around the Mediterranean basin receive similar total annual amounts of rainfall compared to northern European sites, but precipitation processes and landscapes are different due to highly concentrated rainfall in time in the southern regions. As a result, the temporal distribution of precipitation can produce noticeably different impacts on natural and social processes across Europe, being of particular interest for water management, floods, soil erosion, water availability for natural ecosystems, etc.

Our results show that, in Europe, daily concentration of precipitation on annual and seasonal scales, expressed by the $\mathrm{CI}$, is characterized by two different spatial gradients. One lies from the north-west to the south-east and is similar for annual, winter, spring and autumn values, and the second lies from north to south and is characteristic during summer. These broad gradients may intensify on subregional scales when leeward exposure coincides with a body of surface water to the east, such as occurs in the western Mediterranean coastland areas along the Iberian Peninsula and the South of France (and to a lesser extent near the Black Sea coast), and also on the Scandinavian Peninsula. In those areas, the land relief may enhance the CI by orographic uplift forcing specific synoptic conditions downward. Low spatial density of stations in some areas of Europe suggests that the main conclusion may not be reliable. On the other hand, local conditions such as orography, land-sea breeze, etc., could account for some unexplained values (such as occur in the Scandinavian Peninsula).

The values of CIs found across Europe are similar to those described in Iran by Alijani et al. (2008), and are clearly lower than those offered by Zhang et al. (2009) in China, who proposed, as a general explanation for differences between results from Martin-Vide (2004) in the Iberian Peninsula and China, that different climate systems and precipitation mechanisms were responsible for rainfall (such as a typhoons).

Finally, as a general rule, it has been suggested that precipitation trends observed in most parts of the world have the same trend sign as annual maximum daily events, but with the trend of heavy precipitation being disproportionately larger than the trend of totals (Easterling et al., 2000). Furthermore, Karl and Trenberth (2003) suggested that, even without any change in total precipitation, there was an increase in the frequency of intense daily precipitation in warmer climates, a fact that would have led to an increase in precipitation concentration. According to these results, precipitation in Europe should have been more concentrated in time during the last decades, but we have not found any clear signal of changes in daily concentration across the continent during the 1971-2010 period. The massive information used in this study, the spatial coherence of the results, and the absence of significant trends (except some areas of western Europe, i.e. France or the north of Spain) suggest that no generalized changes have occurred in daily precipitation concentration across Europe in the period examined. We have analysed only the last $40 \mathrm{yr}$, and the signal of change in daily precipitation concentration could be time dependent. Further analyses including a longer period would be welcome, although unfortunately daily information would be scarce. 


\section{Conclusions}

The analyses of daily precipitation concentration across Europe during 1971-2010 in a massive dataset show a generalized global pattern of CIs from the north-west (lower values) to the south-east (higher values) on annual, winter, spring and autumn scales, while a north-south oriented gradient has been observed in summer

The maximum daily concentration values are located in the western Mediterranean basin, along the eastern coastland of Spain and southern coastland of France, while the lower values are located on the Scandinavian Peninsula.

The precipitation concentration index reflects different climate types and precipitation regimes, from lower values in oceanic climates on the north-western coast of Europe, to more irregular values (highly concentrated rainfall) under Mediterranean climate types to the south.

No clear signal and spatial pattern of trends in CI have been detected on annual and seasonal scales, except at subregional levels. The results suggest that daily precipitation distribution did not changed significantly in Europe during the 1971-2010 period.

Acknowledgements. Contact Grant Sponsor Ministerio de Ciencia e Innovación (Spanish Goverment) and FEDER, project Impactos Hidrológicos del Calentamiento Global en España (HIDROCAES) (CGL2011-27574-C02-01) and project CGL2011-29263-C02-01 \& 2009SGR443 . Gobierno Regional de Aragón DGA-FEDER (Grupo de Investigación Consolidado "Clima, Agua, Cambio Global y Sistemas Naturales"). Nicola Cortesi is FPI-PhD student supported by Ministerio de Cultura, (Spanish Goverment).

Edited by: R. Crockett

Reviewed by: two anonymous referees

\section{References}

Alijani, B., O’Brien, J., and Yarnal, B.: Spatial analysis of precipitation intensity and concentration in Iran, Theor. Appl. Climatol., 94, 107-124, 2008.

Alpert, P., Ben-Gai, T., Baharad, A., Benjamini, Y., Yekutieli, D., Colacino, M., Diodato, L., Ramis, C., Homar, V., Romero, R., Michaelides, S., and Mases, A.: The paradoxical increase of Mediterranean extreme daily rainfall in spite of decrease, Geophys. Res. Lett., 29, 11, doi:10.1029/2001GL013554, 2002.

Brooks, C. and Carruthers, N.: Handbooks of statistical methods in meteorology, Meteorological Office, London, 412 pp., Great Britain Meteorological Office, Publication official 538, 1953.

Brunet, M., Sigró, J., Jones, P. D., Saladie, O., Aguilar, E., Moberg, A., Lister, D., and Walther, A.: Long-term changes in extreme temperatures and precipitation in Spain, Contribution to Science, 3, 331-342, 2007.

Brugnara, Y., Brunetti, M., Maugeri, M., Nanni, T., and Simolo, C.: High-resolution analysis of daily precipitation trends in the central Alps over the last century, Int. J. Climatol., doi:10.1002/joc.2363, i32, 1406-1422, 2012.
Brunetti, M., Buffoni, L., Maugeri, M., and Nanni, T.: Precipitation intensity Trends in Northern Italy, Int. J. Climatol., 20, 1017 1031, 2000.

Brunetti, M., Maugeri, M., and Nanni, T.: Changes in total precipitation, rainy days and extreme events in northeastern Italy, Int. J. Climatol., 21, 861-871, 2001.

Brunetti, M., Maugeri, M., Monti, F., and Nanni, T.: Changes in daily precipitation frequency and distribution in Italy over the last 120 years, J. Geophys Res., 109, D05, doi:10.1029/2003JD004296, 2004.

Brunetti, M., Caloiero, T., Coscarelli, R., Gullà, G., Nanni, T., and Simolo, C.: Precipitation variability and change in the Calabria region (Italy) from a high resolution daily dataset, Int. J. Climatol., doi: 10.1002/joc.2233, 32, 57-73, 2012.

Burgueño, A., Martínez, M., Serra, C., and Lana, X.: Statistical distributions of daily rainfall regime in Europe for the period 19512000, Theor. Appl. Climatol., 102, 213-226, 2010.

Costa, A. C. and Soares, A.: Trends in extreme precipitation indices derived from a daily rainfall database for the South of Portugal, Int. J. Climatol., 29, 1956-1975, 2009.

Durao, R. M., Pereira, M. J., Costa, A., Delgado, J., del Barrio, G., and Soares, A.: Spatial-temporal dynamics of precipitation extremes in southern Portugal: a geostatistical assessment study, Int. J. Climatol., 30, 1526-1537, 2010.

Easterling, D., Gerald, R., Meehl, A., Parmesan, C., Changnon, S., Karl, T., and Mearns, O. L.: Climate Extremes: Observations, Modeling, and Impacts, Science, 289, 2068-2074, 2000.

Forland, E. J., Alexandersson, H., Drebs, A., Hanssen-Bauer, I., Vedin, H., and Tveito, O. E.: Trends in maximum 1-day precipitation in the Nordic region, DNMI - Report 14/98 KLIMA, 1998

Gallego, M. C., García, J. A., Vaquero, J. M., and Mateos, V. L.: Changes in frequency and intensity of daily precipitation over the Iberian Peninsula, J. Geophys Res., 111, D24105, doi:10.1029/2006JD007280, 2006.

Gonzalez-Hidalgo, J. C., de Luis, M., Raventós, J., and Sánchez, J. R.: (2003): Daily rainfall trend in the Valencia Region of Spain, Theor. Appl. Climatol., 75, 117-130, 2003.

Gonzalez-Hidalgo, J. C., Cortesi, N., and Brunetti, M.: Monthly contribution of largest daily events of precipitation (19562005) across Mediterranean basin, Geophys. Res. Abstr., 13, EGU2011-4182, 2011a.

Gonzalez-Hidalgo, J. C., Brunetti, M., and de Luis, M.: A new tool for monthly precipitation analysis in Spain: MOPREDAS database (Monthly precipitation trends December 1945-November 2005), Int. J. Climatol., 31, 715-731, 2011 b.

Groisman, P. Y., Knight, R. W., Easterling, D. R., Karl, T. R., Hegerl, G. C., and Razuvaev, V. N.: Trends in intense precipitation in the climate record, J. Climate, 18, 1326-1350, 2005.

Jolliffe, I. T. and Hope, P. B.: Bounded bivariate distributions with nearly normal marginal, Amer. Stat., 50, 17-20, 1996.

Haylock, M. R. and Goodess, C. M.: Interannual variability of European extreme winter rainfall and links with the mean large scale circulation, Int. J. Climatol., 24, 759-776, 2004.

Karl, T. R. and Trenberth, K. E.: Modern global climate change, Science, 302, 1719-1723, 2003.

Karl, T. R. and Knight, R. W.: Secular trends of precipitation amount, frequency, and intensity in the United States, BAMS, 79, 231-241, 1998. 
Karl, T. R., Knight, R. W., Easterling, D. R., and Quayle, R. G.: Indices of climate change for the United States, BAMS, 77, 279292, 1996.

Kioutsioukis, I., Melas, D., and Zerefos, C.: Statistical assessment of changes in climate extremes over Greece (1955-2002), Int. J. Climatol., doi:10.1002/joc.2030, 30, 1723-1737, 2010.

Klein-Tank, A. M. G. and Konnen, G. P.: Trends in indices of daily temperature and precipitation ex.tremes in Europe, 1946-1999, J. Climate, 16, 3665-3680, 2003.

Klein-Tank, A. M. G., Wijngaard, J. B., Können, G. P., Böhm, R., Demarée, G., Gocheva, A., Mileta, M., Pashiardis, S., Hejkrlik, L., Kern-Hansen, C., Heino, R., Bessemoulin, P., MüllerWestermeier, G., Tzanakou, M., Szalai, S., Palsdottir, T., Fitzgerald, D., Rubin, S., Capaldo, M., Maugeri, M., Leitass, A., Bukantis, A., Aberfeld, R., Van Engelen, A.F.V., Forland, E., Mietus., M., Coelho, F., Mares, C., Razuvaev, V., Nieplova, E., Cegnar, T., López, J. A., Dahlström, B., Moberg, A., Kirchhofer, W., Ceylan, A., Pachaliuk, O., Alexander, L. V., and Petrovic, P.: Daily dataset of 20th-century surface air temperature and precipitation series for the European Climate Assessment, Int. J. Climatol., 22, 1441-1453, 2002.

Klok, E. J. and Klein-Tank, A. M. G.: Updated and extended European dataset of daily climate observations, Int. J. Climatol., 29, 1182-1191, 2008.

Kundzewicz, Z. W., Radziejewski, M., and Pińskwar, I.: Precipitation extremes in the changing climate of Europe, Clim. Res., 31, 51-58, 2006.

Lionello, P. and Giorgi, F.: Winter precipitation and cyclones in the Mediterranean region: future climate scenarios in a regional simulation, Adv. Geosci., 12, 153-158, doi:10.5194/adgeo-12-1532007, 2007.

Martin-Vide, J.: Spatial distribution of a daily precipitation concentration index in peninsular Spain, Int. J. Climatol., 24, 959-971, 2004.

Moberg, A., Jones, P. D., Lister, D., Walther, A., Brunet, M., Jacobeit, J., Alexander, L. V., Della-Marta, P. M., Luterbacher, J., Yiou, P., Chen, D., Klein-Tank, A. M. G., Saladié, O., Sigró, J., Aguilar, E., Alexandersson, H., Almarza, C., Auer, I., Barriendos, M., Begert, M., Bergström, H., Bömhm, R., Butler, C. J., Caesar, J., Drebs, A., Founda, D., Gestengarbe, F. W., Micela, G., Maugeri, M., Osterle, H., Pandzic, K., Petrakis, M., Srnec, L., Tolasz, R., Tuomenvirta, H., Werner, P. C., Linderholm, H., Philipp, A., Wanner, H., and Xoplaki, E.: Indices for daily temperature and precipitation extremes in Europe analysed for the period 1901-2000, J. Geophys Res., 111, D22106, doi:10.1029/2006JD007103, 2006.
Norrant, C. and Douguedroit, A.: Monthly and daily precipitation trends in the Mediterranean (1950-2000), Theor. Appl. Climatol., 83, 89-106, 2006.

Olascoaga, M. J.: Some aspects of Argentine rainfall, Tellus B, 2, 312-318, 1950.

Osborn, T. J., Hulme, M., Jones, P. D., and Basnett, T. A.: Observed trends in the daily intensity of United Kingdom precipitation, Int. J. Climatol., 20, 347-364, 2002.

Räisänen, J., Hason, U., Ullerstig, A., Döscher, R., Graham, L.P., Jones, C., Meier, H., Samuelsson, P., and Willén, U.: European climate in the late twenty-first century: regional simulations with two driving global models and two forcing scenarios, Clim. Dynam., 22, 13-31, 2004.

Reiser, H. and Kutiel, H.: Rainfall uncertainty in the Mediterranean: time series, uncertainty, and extremes, Theor. Appl. Climatol., 104, 357-375, 2010.

Riehl, H.: Some aspects of Hawaiian rainfall, BAMS, 30, 76-187, 1949.

Rodrigo, F.: Changes in the probability of extreme daily precipitation observed from 1951 to 2002 in the Iberian Peninsula, Int. J. Climatol., 30, 1512-1525, 2010.

Rodrigo, F. S. and Trigo, R. M.: Trends in daily rainfall in the Iberian Peninsula from 1951 to 2002, Int. J. Climatol., 27, 513529, 2007.

Suppiah, R. and Hennessy, K. J.: Trends in total rainfall, heavy-rain events and number of dry days in Australia, 1910-1990, Int. J. Climatol., 10, 1141-1164, 1998.

Trenberth, K. E., Dai, A., Rasmussen, R. M., and Parsons, D. B.: The changing character of precipitation, BAMS, 1205-1217, 2003.

Toreti, A., Xoplaki, E., Maraun, D., Kuglitsch, F. G., Wanner, H., and Luterbacher, J.: Characterisation of extreme winter precipitation in Mediterranean coastal sites and associated anomalous atmospheric circulation patterns, Nat. Hazards Earth Syst. Sci., 10, 1037-1050, doi:10.5194/nhess-10-1037-2010, 2010.

Zhang, X., Zwiers, F. W., Hegerl, G. C., Lambert, F. H., Gillett, N. P., Solomon, S., Stott, P. A., and Nozawa, T.: Detection of human influences on twentieth-century precipitation trends, Nature, 448 , 461-465, 2007.

Zhang, Q., Xu, C. Y., Gemmer, M., Chen, Y. Q., and Liu, C. L.: Changing properties of precipitation concentration in the Pearl River basin, China, Stochastic Environ. Res. Risk Assess., 23, 377-385, 2009.

Zolina, O., Kapala, A., Simmer, C., and Gulev, S. K.: Analysis of extreme precipitation over Europe from different reanalysis: a comparative assessment, Global Planet. Change, 44, 129-161, 2004. 